\section{Facile Synthesis of N-Permethylspermine and N-Permethylspermidine from their Unmethylated Precursors}

\author{
Angelo G. Giumanini, Giuseppe Chiavari, \\ and Franco L. Scarponi
}

Centro di Gascromatografia-Spettrometria di Massa and Istituto Chimico G. Ciamician, Università di Bologna, 40126 Bologna, Italy

(Z. Naturforsch. 30b, 820-821 [1975]; received April 11, 1975)

Mass Spectrometry, Spermine, Spermidine, Methylation, N-Permethylspermidine

A rapid synthesis of the title compounds employing formaldehyde and sodium borohydride in acidic aqueous solution in combination with the unmethylated amines is described. High yields and the characteristics of the methylated amines allow the application of the method to gas chromatographic and mass spectrometric analyses.

Although a few $\mathrm{N}$-permethylated $\alpha, \omega$-diamines showed some neuromuscular blocking ${ }^{1}$ and hypotensive $^{2}$ activity, it is surprising to find that no published report is yet available about the $\mathrm{N}$ permethyl derivatives of the biologically important polyamines spermine (1) and spermidine (2). Moreover, only one synthesis was described for the Npermethylspermine (3), but the compound has received a scant characterization ${ }^{3}$. N-Permethylspermidine (4) is not known from the literature.

We wish to report here a straightforward and unexpensive method of preparation of both 3 and 4 from the unmethylated precursors in excellent yields. Our synthesis follows an early suggestion made by BIEMANN 4 for the N-methylation of protein free amino groups.

A typical preparative procedure is as follows: Sulphuric acid ${ }^{5}$ (13.2 mmol, ca. $3 \mathrm{M}$ ) was added to the amine ${ }^{6}$ to be methylated $(2.23 \mathrm{mmol})$. Formaldehyde $(40 \%$ in water, $2.5 \mathrm{ml}, c a .33 \mathrm{mmol})$ was added at room temperature to the solution kept in Erlenmeyer flask $(50 \mathrm{ml})$ equipped with a $2 \mathrm{~cm}$ magnatic bar to provide adequate stirring. Solid sodium borohydride $^{7}(21 \mathrm{mf})$ was added slowly portionwise during $20 \mathrm{~min}$ with temperature control $\left(10-20^{\circ} \mathrm{C}\right)$, then the reaction mixture was made strongly acidic with $3 \mathrm{M}$ sulphuric acid ${ }^{5,8}$, extracted with ether $(2 \times 3 \mathrm{ml})$, made strongly basic with solid potassium hydroxide and reextracted with ether $(5 \times 10 \mathrm{ml})$. Average yields are above $80 \%$

Requests for reprints should be sent to Prof. A. G. Giumanini, Centro di Gascromatografia-Spettrometria di Massa, Università di Bologna, I-40126 Bologna, Italy. for 3 and above $90 \%$ for 4 , as determined by gaschromatography ${ }^{9}$. If pure starting materials were used, the reaction products are chromatographically homogeneous. Pure amines (3) and (4) may be isolated from their dried $\left(\mathrm{Na}_{2} \mathrm{SO}_{4}\right)$ ether solutions after evaporation of the solvent by vacuum distillation. In the described small preparation, we distilled the amines from a microapparatus on an oil bath at controlled temperature ${ }^{10}$.

The infrared spectra of $\mathbf{3}$ and $\mathbf{4}$ are practically identical (Fig. 1), as well as the proton magnetic resonance spectra with the obvious exclusion of the integral values. All the methyl protons locations coincide in deuterochloroform, but the protons of the lone methyls may be separated from those of the geminal methyls in the spectrum by addition of excess trifluoroacetic acid, as shown in Fig. 2. The mass spectra of $\mathbf{3}$ and $\mathbf{4}$ exhibit weak, but distict parent ions, with a complex fragmentation pattern dominated by the ion at $m / e 58$ at $70 \mathrm{eV}$. At lower ionization energies $(15-20 \mathrm{eV})$ several transitions are enhanced and the parent ions are relatively intense (Fig. 3).

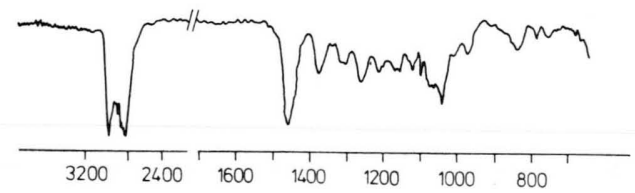

Fig. 1. The infrared spectrum of $\mathrm{N}$-permethylspermine (3), recorded as a neat liquid between $\mathrm{NaCl}$ windows.

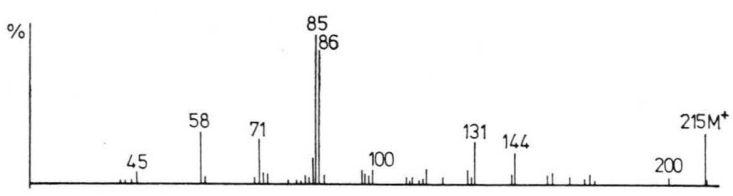

Fig. 2. Mass spectrum of N-permethylspermidine (4). Electron energy $15 \mathrm{eV}$. Chamber temp. $270^{\circ} \mathrm{C}$.

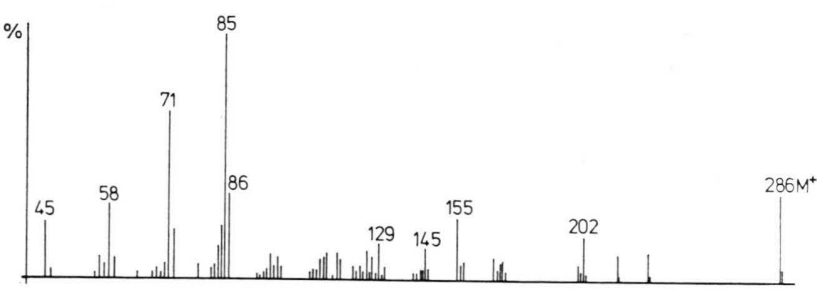

Fig. 3. Mass spectrum of N-permethylspermine (3). Electron energy $15 \mathrm{eV}$. Chamber temp. $270{ }^{\circ} \mathrm{C}$.

The fact that the N-permethylderivatives (3) and (4) of spermine (1) and spermidine (2) can be easily prepared in near to quantitative yields in aqueous solution, from which a standard acid-base separa- 
tion works beautifully, coupled with the excellent gaschromatographic and mass spectrometric properties they exhibit not only in comparison with the familiar N-pertifluoroacetylderivatives ${ }^{11}$, but also with the free amines ${ }^{12}$, and the stability against water and oxygen, makes them superior candidates

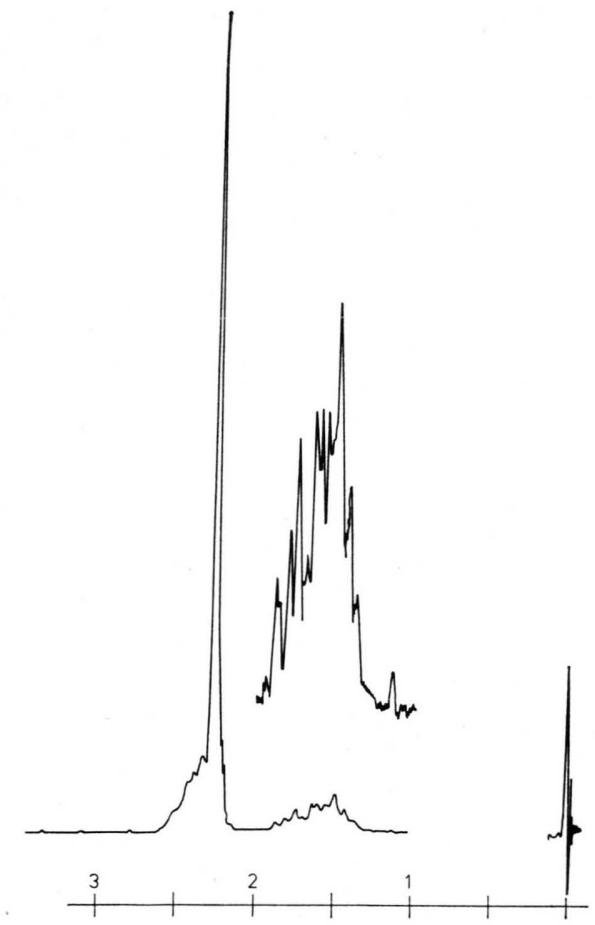

Fig. 4. The proton magnetic resonance spectrum of $\mathrm{N}$-permethylspermine in deuterochloroform at $60 \mathrm{MHz}$. The large singlet is due to the methyl protons resonances, which are partially superimposed on the $\mathrm{N}$-methylene protons resonances. Different methyl protons are indistinguishable. The peaks for the C-methylene protons are also shown at higher gain. The peak to the right is due to tetramethylsilane, an internal standard.

1 C. J. Cavallito, A. P. Gray, and E. E. Sprinner, J. Amer. Chem. Soc. 76, 1862 [1954].

2 A. P. Phillips, J. Amer. Chem. Soc. 77, 1693 [1955].

3 H. W. Dudley, O. Rosenheim, and W. W. StarLING, Biochem. Journ. 20, 1086 [1926].

-4 K. Biemann, "Applications to Natural Products and Other Problems in Organic Chemistry" in "Mass Spectrometry of Organic Ions" by F. W. McLaFFERTy, Academic Press, New York 1963. No experimental details are given.

5 Hydrochloric acid should be avoided owing to the potential formation of the extremely toxic and volatile $\alpha, \alpha^{\prime}$-dichlorodimethylether.

6 The free unmethylated amines absorb water and carbon dioxide from air very quickly.

7 This reagent is moderately unstable in acidic water solutions giving off hydrogen: the reaction must therefore be performed away from flames and sparks in a well ventilated hood. for an accurate and fast qualitative and quantitative method of determination of $\mathbf{1}$ and $\mathbf{2}$ in biological fluids, a need strongly felt nowadays in biological laboratories ${ }^{12}$.

This work was supported in part by an Italian National Research Council grant (to A.G.G., 1975).

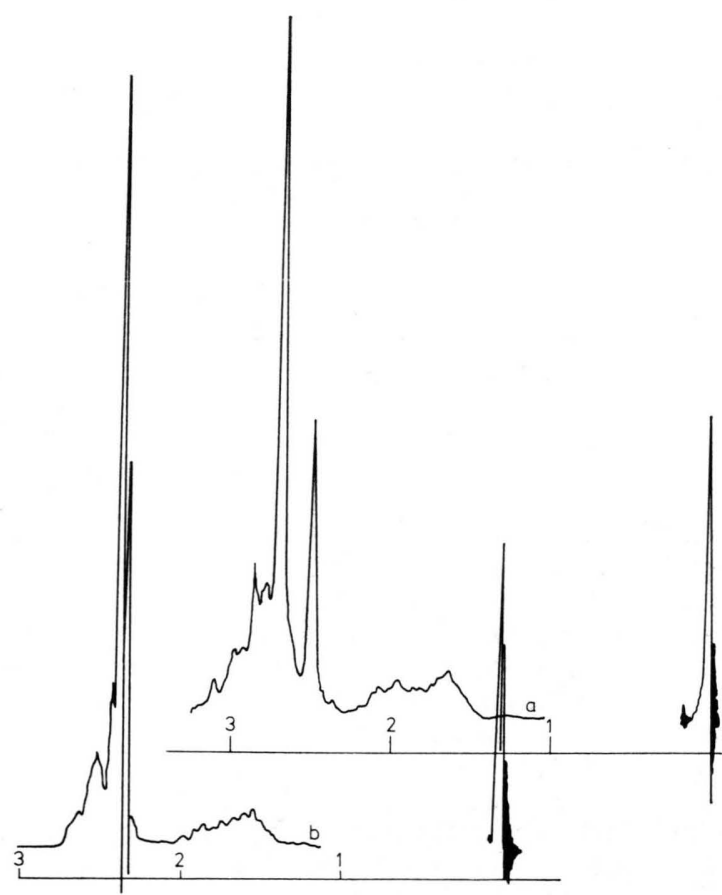

Fig. 5. Curve a showns the effect of the addition of excess trifluoroacetic acid to a deuterochloroform solution of $\mathrm{N}$-permethylspermine (3) on the proton magnetic resonance spectrum, where the two types of methyl groups are neatly distinct. A lesser amount of the acid (curve b) causes a smaller separation of the methyl resonances.

8 Acidification and ether extraction at this point of the work-up is necessary to get rid of a volatile boron compound which codistilled with the amine, infrared bands at $2220-2500 \mathrm{~cm}^{-1}$ (B-H bond stretching).

9 The choice of the column packing is not at all critical for the methylated derivatives. We used e.g. a $1 \mathrm{~m}$ by $0.25 \mathrm{~cm}$ copper column packed with Carbowax $20 \mathrm{M}(10 \%)-\mathrm{KOH}(5 \%)$ on $80-100$ mesh Chromosorb W, operating at $140-170^{\circ} \mathrm{C}$, with a flow rate of $15 \mathrm{ml} / \mathrm{min}$ (nitrogen). The injector temperature was kept at $300{ }^{\circ} \mathrm{C}$.

10 The pressure was $c a$. 0.15 torr; 3 distilled with the oil at ca. $140{ }^{\circ} \mathrm{C}, 4$ at ca. $70^{\circ} \mathrm{C}$.

11 T. W ALLE, in "Polyamines in Normal and Neoplastic Growth", edited by D. H. Russell, p. 355, Raven Press, New York 1973.

12 See the book quoted in ref. 11 and S. S. Cohen, "Introduction to the Polyamines", Prentince-Hall, New Jersey 1971. 